\title{
GAME EDUKASI LITERASI INFORMASI (GERASI) UNTUK MENGENALI INFORMASI HOAX PADA PELAJAR
}

\author{
Anis Safitri \\ Universita Negeri Yogyakarta \\ Email: irtifassina@gmail.com \\ Anisa Fitri \\ Universita Negeri Yogyakarta \\ Email: anisaft9@gmail.com \\ Bayu Septian \\ Universitas Negeri Yogyakarta \\ bayuseptian020999@gmail.com
}

\begin{abstract}
ABSTRAK
Indonesia saat ini sedang darurat informasi hoax. Berdasarkan data Kemenkominfo tahun 2017, 800.000 situs di Indonesia telah terindikasi sebagai penyebar informasi hoax. Dewasa ini informasi hoax dan informasi fakta yang banyak beredar di dunia maya sangat sulit dibedakan. Salah satu penyebabnya yaitu banyaknya pengguna gawai yang sembarangan membagikan suatu informasi tanpa melakukan pengecekan terlebih dahulu. Alhasil, informasi hoax yang tersebar menimbulkan kehebohan luar biasa. Literasi informasi memegang peran penting dalam menghadapi banyaknya informasi hoax yang tersebar. Menurut American LibraryAssociation, literasi informasi adalah serangkaian kemampuan yang dibutuhkan seseoranguntuk menyadari kapan informasi dibutuhkan dan memiliki kemampuan untuk menemukan, mengevaluasi, dan menggunakan informasi yang dibutuhkan secara efektif. Oleh karena itu, Game Edukasi Literasi Informasi (GERASI) menjadi solusi yang tepat. Konsep dari GERASIadalah: (1) Penyajian pengetahuan di setiap level mengenai etika menyebarkan informasi dan tips mengidentifikasi informasi hoax, (2) Pelatihan menjadi pengguna gawai yang menerapkan etika sebelum membagikan informasi, (3) Pembelajaran mengenai pentingnya daya kritis dalam memahami suatu gambar dan berita yang beredar di dunia maya. Game edukasi ini juga menyediakan tutorial penggunaan Turn Back Hoax, website buatan Komunitas Anti Hoax yang berfungsi sebagai tempat pelaporan berita hoax. Harapannya GERASI dan Turn Back Hoax dapat menjadi fasilitator dalam membentuk karakter pengguna gawai yang cerdas dan berliterasi.
\end{abstract}

Kata Kunci: Game Edukasi, Literasi Informasi, Informasi Hoax.

\begin{abstract}
Currently, Hoax in Indonesia is very urgent. According to the data from Kemenkominfo 2017, in total 800.000 sites in Indonesia was indicated as a hoax information disseminator. Nowadays, it is difficult to differentiate hoax and fact in the Internet. One of the cause is most of smartphone users shared the information without recheck them. Finally, it caused the great excitement. Information literacy is very important to face the scattered hoax. American Library Association defines that information literacy is a set of abilities requiring individuals to recognize when information is needed and have the ability to locate, evaluate, and use effectively the needed information. Based on the problem, "Game EdukasiLiterasiInformasi (GERASI)" can be the appropriate solution. The concept of GERASi are: (1) the knowledge presentation in each level is about the ethic in sharing information and tips in identifying the hoax, (2) the training for being the smartphone
\end{abstract}

Scripta : Jurnal Ilmiah Mahasiswa

Fakultas Ilmu Sosial dan Ilmu Politik

Universitas Bangka Belitung

ISSN: 2656-9809 
users who use the ethic before sharing the information, (3) the learning about the important of critical thinking in understanding hoax pictures and news in the Internet. The educative game also provides the tutorial to use "Turn Back Hoax Website" made by Anti Hoax Community as the place for reporting the hoax. We hope that GERASI and Turn Back Hoax can be the facilitator in building the characters of smartphone users who are smart and iteration.

Keywords: Game Education, Information Literacy, Hoax Information.

\title{
PENDAHULUAN
}

Pada abad kedua puluh satu perkembangan gawai (gadget) begitu pesat. Teknologi ini sudah dijadikan kebutuhan pokok sehari-hari bagi masyarakat Indonesia. Bahkan, smartphone termasuk salah satu gawai yang banyak digunakan oleh masyarakat Indonesia. Dilansir melalui www.kominfo.go.id, Lembaga Riset Digital Marketing Emarketer memperkirakan pada 2018 jumlah pengguna aktif smartphone di Indonesia lebih dari 100 juta orang. Dengan jumlah sebesar itu, Indonesia akan menjadi negara dengan pengguna aktif smartphone terbesar keempat di dunia setelah Cina, India, dan Amerika.

Frekuensi penggunaan smartphone yang tinggi menyebabkan interaksi di dunia maya lebih sering dilakukan daripada interaksi sosial di dunia nyata. Hal ini menyebabkan penyebaran informasi di dunia maya sangat cepat. Semua informasi yang tersebar pun belum tentu pasti kebenarannya. Informasi yang tersebar di dunia maya memiliki dua jenis, yaitu informasi fakta dan informasi hoax. Akhir-akhir ini, Indonesia sedang darurat informasi hoax. Berdasarkan data Kemenkominfo tahun 2017, terdapat 800.000 situs di Indonesia yang telah terindikasi sebagai penyebar informasi hoax. Banyaknya informasi hoax yang beredar menimbulkan kehebohan, kebingungan, bahkan memunculkan ujaran kebencian.

Mirisnya yaitu banyak pengguna gawai yang mudah percaya pada informasi yang masih samar kebenarannya. Menurut Menkominfo Rudiantara, mayoritas orang Indonesia menomorsatukan rasa senang. Jadi, jika melemparkan isu ingin dianggap yang pertama. Buktinya, kirim lewat WhatsApp, Facebook, Twitter, dan sebagainya (www.kompas.com, 13/2/2017). Masih disarikan melalui surat kabar online yang sama, pengamat media sosial, Nukman Luthfie, mengatakan bahwa pengguna mobile phone ketika melihat berita hanya memerhatikan judul kemudian disebarkan. Ini fakta, karakter yang menarik dan tidak pernah terjadi sebelumnya. Selain kebiasaan berbagi secara cepat, pola baca masyarakat

\author{
Scripta : Jurnal Ilmiah Mahasiswa \\ Fakultas Ilmu Sosial dan Ilmu Politik \\ Universitas Bangka Belitung \\ ISSN: 2656-9809
}


juga berubah total. Jika membaca buku halaman berapa dan koran alinea berapa, pembaca berita online cenderung membaca secara cepat.

Game Edukasi Literasi Informasi (GERASI) merupakan salah satu solusi untuk meningkatkan kemampuan literasi informasi bagi pengguna gawai. Game edukasi ini dirancang untuk meningkatkan budaya kritis, cerdas, dan bijak saat berinteraksi di dunia maya. Melalui game edukasi ini, pengguna gawai juga dilatih agar mampu memanfaatkan informasi yang didapat dengan sebaik-baiknya.

\section{METODE PENULISAN}

\section{Pengumpulan Data}

Metode penulisan bersifat studi pustaka. Studi pustaka adalah metode pencarian data dari buku, browsing internet, jurnal, makalah atau literatur-literatur lain yang berkaitan dengan teori dasar dari sistem yang sedang dibuat, dan dokumen yang berkaitan dengan data yang diperlukan untuk penelitian maupun perancangan aplikasi. Penulis juga menyebarkan angket/kuesioner untuk mendapatkan data pendukung.

\section{Populasi dan Sampel}

Sugiarto, dkk pada tahun 2010 (dalam Indrawati, 2014), telah mengungkapkan bahwa populasi adalah keseluruhan unit atau individu dalam ruang lingkup yang diteliti, sedangkan sampel adalah sebagian dari populasi yang ingin diteliti yang ciri-ciri dan keberadaannya diharapkan mampu mewakili atau menggambarkan ciri-ciri dan keberadaan populasi yang sebenarnya. adalah para pengguna gawai di Yogyakarta, sedangkan sampel yang kami ambil adalah pengguna gawai di Yogyakarta yang dipilih secara acak untuk mengisi angket yang telah kami buat.

\section{Prosedur Kerja Studi Pustaka}

a. Mengumpulkansumber-sumberkepustakaanberupahasilpenelitian.

b. Membacasumber-sumberkepustakaanhasilpenelitian.

c. Membuatkesimpulandariberbagaisumberpustaka. 


\section{Kerangka Berpikir}

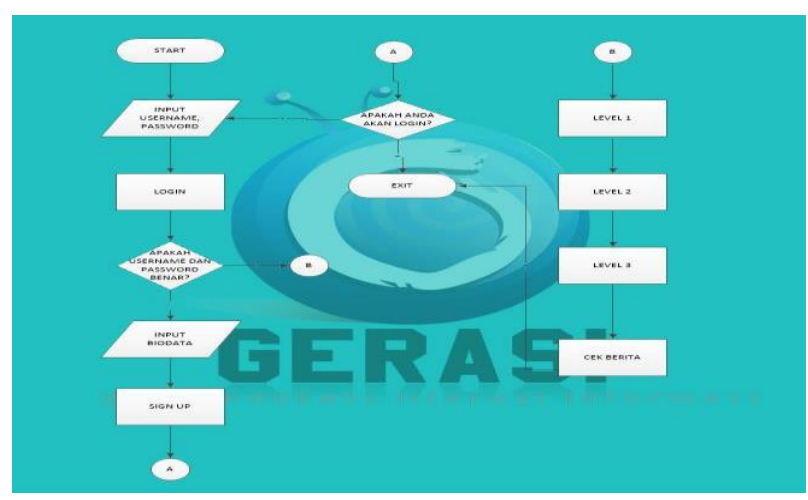

Gambar 1. Flowchart GERASI

\section{HASIL PENELITIAN DAN PEMBAHASAN}

\section{Deskripsi Data}

Dalam menyusun karya tulis ilmiah berjudul "Game Edukasi Literasi Informasi (GERASI) untuk Mengenali Informasi Hoax Pada Pelajar", penulis menggunakan metode studi pustaka. Penulis mulai mengumpulkan data baik dari media cetak maupun elektronik pada 20 Agustus 2018.

Selain menggunakan metode studi pustaka, penulis juga menyebar kuesioner/angket untuk masyarakat Yogyakarta yang notabene pengguna gawai. Sampel yang penulis ambil adalah pengguna gawai di Yogyakarta yang dipilih secara acak untuk mengisi angket yang telah dibuat. Penulis mendapatkan 65 responden dari pengguna gawai di Yogyakarta untuk mendukung penelitian ini. Responden yang telah mengisi berasal dari berbagai kalangan, diantaranya pelajar, mahasiswa, karyawan, dan ibu rumah tangga.

Hasil dari angket/kuesioner yang kami sebar menyatakan bahwa sebanyak 54\% pengguna gawai di Yogyakarta sering menerima informasi yang belum pasti kebenarannya. Sedangkan untuk $46 \%$ lainnya menyatakan pernah menerima informasi yang belum pasti kebenarannya. Pengguna gawai di Yogyakarta juga menyatakan bahwa mereka sering menerima informasi yang belum pasti kebenarannya melalui media sosial. Hal ini dibuktikan bahwa sebanyak 97\% menyatakan bahwa mereka sering mendapatkan informasi tersebut melalui Facebook, Instagram, WhatsApp, Twitter, dll. Sedangkan sebanyak 3\% penggunagawai di Yogyakarta sering mendapatkannya melalui media cetak. Dariangket/kuesioner yang disebar, kami juga mendapatkan fakta bahwa

Scripta : Jurnal Ilmiah Mahasiswa

Fakultas Ilmu Sosial dan Ilmu Politik

Universitas Bangka Belitung

ISSN: 2656-9809 
sebanyak $75 \%$ pengguna gawai di Yogyakarta kadang-kadang membaca suatu informasi hingga selesai. Hanya $16 \%$ yang memiliki kebiasaan membaca informasi hingga selesai dan 9\% lainnya menyatakan tidak pernah membaca suatu informasi hingga selesai.

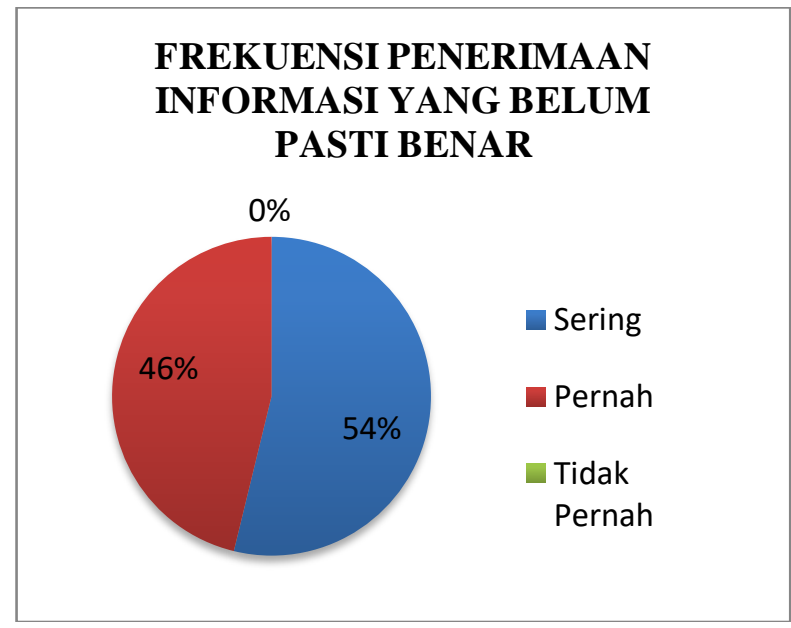

Gambar 2. Frekuensi Penerimaan Informasi yang Belum Pasti Benar

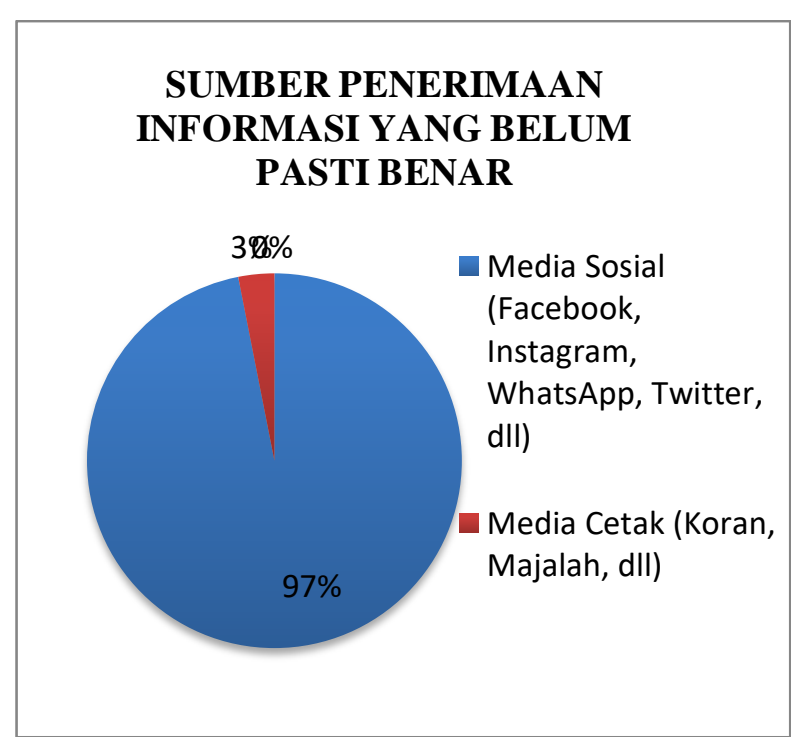

Gambar 3. Sumber Penerimaan Informasi yang Belum Pasti Benar

Scripta : Jurnal Ilmiah Mahasiswa Fakultas Ilmu Sosial dan Ilmu Politik Universitas Bangka Belitung ISSN: 2656-9809 


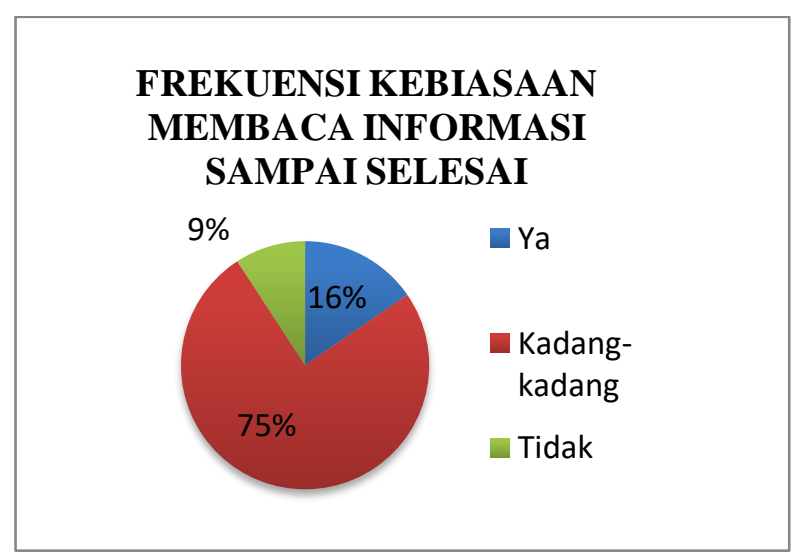

Gambar 4. Frekuensi Kebiasaan Membaca Informasi Sampai Selesai

\section{Desain Game Edukasi Literasi Informasi (GERASI)}

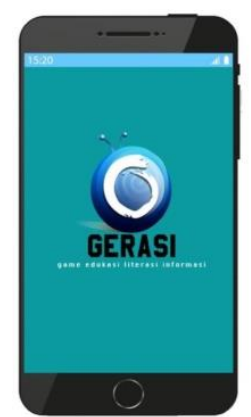

Gambar5. Tampilan Awal

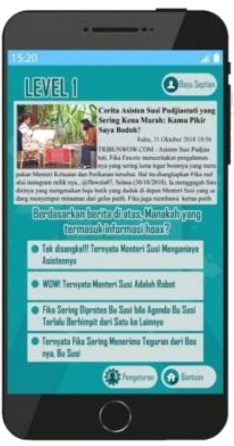

Gambar 9. Level 1

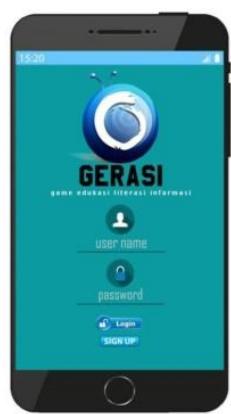

Gambar 6. Tampilan Log in

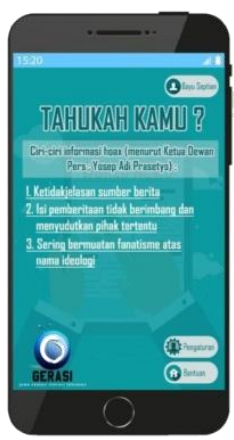

Gambar 10. Ciri-ciri informasi hoax

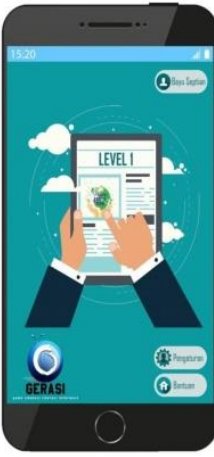

Gambar 7. Level 1

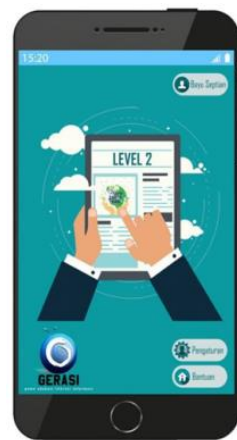

Gambar 11. Level 2

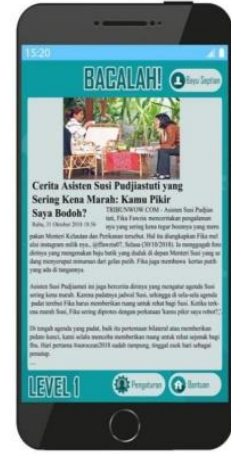

Gambar 8. Level 1

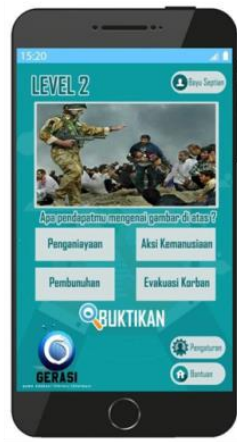

Gambar 12. Level 2

Scripta : Jurnal Ilmiah Mahasiswa Fakultas Ilmu Sosial dan Ilmu Politik Universitas Bangka Belitung ISSN: 2656-9809 


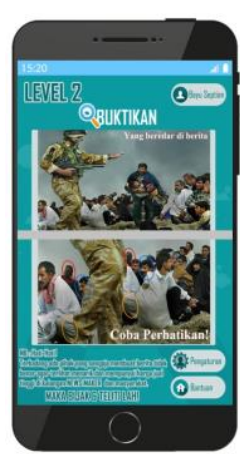

Gambar 13. Level

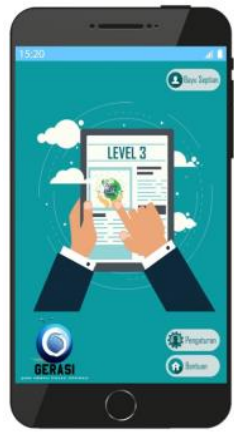

Gambar 14. Level 3

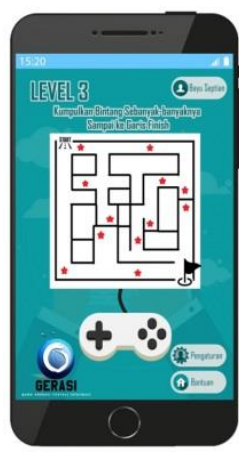

Gambar 15. Level 3

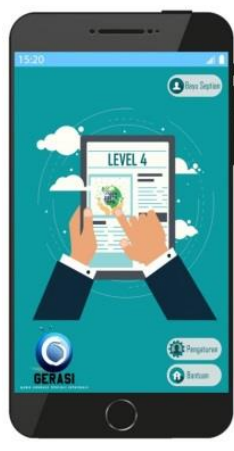

Gambar 16. Level 4

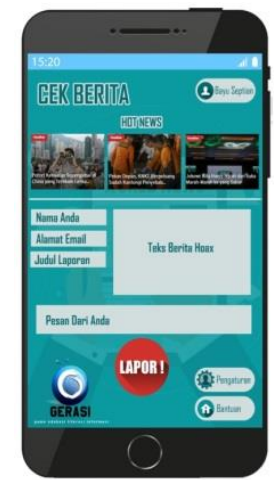

Gambar 17.CekBerita

Berdasarkan hasil angket yang disebar, informasi hoax telah menjangkiti para pengguna gawai di Yogyakarta. Tingkat literasi saat berselancar di media sosial juga kurang. Oleh karena itu, penulis ingin menawarkan sebuah solusi untuk memecahkan masalah tersebut, yaitu dengan dibuatnya Game Edukasi Literasi Informasi.

Game ini bukanlah sekadar permainansemata. Game ini mengajak pemainnya agar kritis ketika menerimainformasi. Sehingga, GERASI dapat dijadikan sarana bermain dan belajar mengenai literasi informasi.

Konsep dari GERASI sangatlah menarik. Di level 1, pemain akan disajikan sebuah kutipan informasi/berita. Setelah informasi tersebut dibaca, pemain dituntut untuk bisa membedakan mana informasi hoax dan informasi fakta. Di akhir level 1 ini, pemain akan diajarkan tips-tips mengidentifikasiinformasihoax.

Selanjutnya, di level 2 pemain akan disajikan sebuah fotoataugambar. Pemain harus menginterpretasikan gambar tersebut sesuai pendapatnya dengan memilih salah satu bubble yang tersedia. Setelah memilih salah satu bubble, pemain bisa memencet tombol

Scripta : Jurnal Ilmiah Mahasiswa

Fakultas Ilmu Sosial dan Ilmu Politik

Universitas Bangka Belitung

ISSN: 2656-9809 
"buktikan" untuk membuktikan apakah interpretasinya benar atau salah. Dari level 2 ini pemain diajarkan untuk tidak mudah mengambil kesimpulan dengan cepat saat menerima suatu gambar atau foto. Contoh yang paling sering ditemui di media sosial adalah sebuah gambar atau foto yang aneh dan unik. Para netizen yang kurang kritis seketika akan percaya dan takjub. Mereka pun tanpa berpikir panjang menyebarluaskan gambar atau foto tersebut. Tak disangka, gambar atau foto tersebut hanyalah hoax. Hal ini bisa dijadikan pembelajaran bahwa sebuah gambar atau foto dapat diambil dari sudut pandang manapun dan tidak menutup kemungkinan mudah direkayasa.

Berikutnya, di level 3 pemain diposisikan berada di sebuah labirin. Di dalam labirin tersebut, pemain harus mengumpulkan bintang sebanyak-banyaknya. Setiap satu bintang yang diambil, pemain akan mendapatkan satu bubble. Bubble tersebut berisi informasi dan tips seputar informasi hoax. Tips-tipsyang diberikan antara lain bagaimana cara mengenali informasi hoax dari segi judul, penulisan, dan konten.

Di level 4, pemain akan diajarkan tutorial penggunaan website Turn BackHoax. Sebelumnya, pemain akan memutar roda warna terlebih dahulu untukmenentukan berita/gambar mana yang ingin dilaporkan. Setelah itu, pemain akan dituntun untuk latihan melaporkan informasi ke website Turn Back Hoax.

Kelebihan Game Edukasi Literasi Informasi (GERASI) adalah game ini dibuat untuk meningkatkan kemampuan literasi dengan cara bermain. Pelajar sebagai pemain secara tidak langsung diajarkan untuk lebih kritis dan cerdas saat berselancar di media sosial.

Menurut penulis, GERASI adalah solusi tepat untuk menjawab permasalahan yang sedang hangat akhir-akhir ini, yaitu mengenai isu hoax. Media pembelajaran berbentuk game sangatlah efektif diterapkan pada pelajar. GERASI ini pun termasuk game pertama di Indonesia yang bertujuan untuk menambah bekal literasi pelajar agar saat berselancar di dunia maya tidak mudah termakan hoax.

Scripta : Jurnal Ilmiah Mahasiswa

Fakultas Ilmu Sosial dan Ilmu Politik

Universitas Bangka Belitung

ISSN: 2656-9809 


\section{SIMPULAN DAN SARAN}

\section{Kesimpulan}

Game Edukasi Literasi Informasi (GERASI) dibuat dengan tujuan untuk meningkatkan kemampuan literasi informasi para pengguna gawai, terutama pelajar. GERASI terdiri dari 4 level yang memiliki konsep pembelajaran berbeda-beda.

\section{Saran}

Untuk pengembangan lebih lanjut, alangkah baiknya GERASI diberikan sistem upgrade otomatis agar lebihmemudahkan pengguna dalam memainkannya. Selain itu, untuk promosi GERASI dapat digencarkan dengan melakukan sosialisasi ke sekolahsekolah.

\section{DAFTAR PUSTAKA}

Arman, R. 2011. Pembuatan Game Edukasi Tentang Matematika Dasar. InstitutBisnis dan

Informatika Stikom.Surabaya.(http://sir.stikom.edu/id/eprint/diakses tanggal 25 Agustus 2018 pukul 19:50 WIB)

Boyle T. 1997. Design for MultimediaLearning. Prentice Hall.

Bundy, A. 2001. For a Clever Country:Information Literacy Diffusion in the $21^{\text {st }}$ Century.

(https://www.library.unesa.edu.au/about/papers/clever/pdf, diakses tanggal 24 Agustus 2018 pukul 21:00 WIB)

Dewi, Ghea Putri Fatma. 2012.Pengembangan Game Edukasi Pengenalan NamaHewan dalam Bahasa Inggris sebagai Media Pembelajaran Siswa SDBerbasis Macromedia Flash. UNY.(https://eprints.uny.ac.id/9505/1/SKRIPSI.pdf, diakses tanggal 25 Agustus 2018 pukul 21:10 WIB)

Handriyantini. 2009. Permainan EdukatifBerbasis Komputer untuk Siswa Sekolah Dasar.

Malang: Sekolah Tinggi.

Hasugian, Jonner. 2008. Urgensi LiterasiInformasi dalam Kurikulum Berbasis Kompetensi di

Perguruan TinggiUniversitas Sumatera Utara. Pustaha:JurnalStudiPerpustakaan

Scripta : Jurnal Ilmiah Mahasiswa

Fakultas Ilmu Sosial dan Ilmu Politik

Universitas Bangka Belitung

ISSN: 2656-9809 
dan

Informasi, Vol.

(puslit2.petra.ac.id/ejournal/index.php/pus/article/view/17231 pada tanggal 25

Agustus2018 pukul 22:00 WIB)

Kevin, Amelia Anada. 2017. JurnalAplikasi Game Edukasi Bahasa BerbasisMacromedia

Flash Menggunakan Metode Waterfall. UniversitasNusantara PGRI

Kediri.(http://simki.unpkediri.ac.id/mahasiswa/file_artikel/2017/70379502fe6ca

7d2eebd2827126a7d3d.pdf, diakses tanggal 25 Agustus 2018 pukul21:00 WIB.

Marwan, M. Ravii. Analisis PenyebaranBerita Hoax di Indonesia. Fakultas IlmuKomunikasi

Universitas Gunadarma.(ravii.staff.gunadarma.ac.id diakses pada tanggal 27 Agustus 2018 pada pukul 21:59WIB)

Respati, Sheila. 2017. Mengapa BanyakOrang Mudah Percaya Berita"Hoax"?. https://nasional.kompas.com/read/2017/01/23/18181951/mengapa.banyak.orang. mudah.percaya.berita.hoax diaksespada tanggal 26 Agustus 2018pada pukul 20:10 WIB.

Rosmalinda, Ruri.2017. Fenomena Penyesatan Berita di Media Sosial dalamartikel ilmiah. WIB.

http://www.seskoad.mil.id/ diakses pada tanggal 24Agustus 2018 pukul 20:10

Vitianingsih, Anik Vega. 2017. GameEdukasi sebagai Media PembelajaranPendidikan Anak

Usia Dini. Teknik Informatika, Fakultas TeknikUniversitas Dr. Soetomo Surabaya. Jurnal INFORM Vol. 1. (https://zenodo.orgdiaksestanggal 25 Agustus 2018pukul 21:20 WIB)

Scripta : Jurnal Ilmiah Mahasiswa Fakultas Ilmu Sosial dan Ilmu Politik Universitas Bangka Belitung ISSN: 2656-9809 